\title{
Analysis of environmental migrants and their mental health
}

\section{in strengthening health systems [version 1; peer review: 2}

\section{approved with reservations]}

\author{
Keren Herrán (D), Dawn Biehler \\ University of Maryland, Baltimore County, Baltimore, MD, USA
}

\begin{tabular}{l}
\hline V1 First published: 24 Nov 2020, 9:1367 \\
https://doi.org/10.12688/f1000research.27272.1 \\
Latest published: 24 Nov 2020, 9:1367 \\
https://doi.org/10.12688/f1000research.27272.1 \\
\hline
\end{tabular}

\section{Abstract}

Background: It is predicted that by 2050 more than 250 million people will have to relocate as a result of climate-related change to their home environment. The existential threat posed by anthropogenic phenomena such as forest fires, floods, sea level rise, drought, and intensified weather events (e.g. tropical storms) has caused a new type of migrant to emerge. Within academic literature, these migrants are referred to as climate migrants, environmental migrants, or eco migrants, among other terms. These individuals' migration journey and this journey's impact on their mental health is currently an understudied research area. This paper summarizes the mental health challenges climate migrants face via a narrative review. Methods: Google Scholar was used as the main search database throughout May, 2020 until authors determined data saturation had been reached. Grey literature was also included. Sources were included if they focused directly on evaluating environmental migrants and their mental health experiences. Academic sources must have been peer-reviewed and published within the past 10 years. Information was coded and evaluated according to the three migration journey stages of before, after, and during relocation.

Results: Main findings include that the slow or sudden degradation of one's surroundings can cause the onset of mental health disorders that are later exacerbated by challenges faced when migrating, such as lack of access to health services. Mental health challenges faced upon reaching destination communities consist mainly of social marginalization and disruption of social ties. Lastly, action items for health systems are outlined and the need for more research on the mental wellbeing of climate migrants throughout their migration journey is stressed.

Conclusions: This review is an urgent call to policymakers, health professionals, and researchers to strengthen health systems by making them more climate resilient and inclusive towards environmental migrants.

\section{Open Peer Review \\ Approval Status ? ? \\ 12

version $1 ?$ ? \\ 24 Nov 2020 view view \\ 1. Pablo Daniel Estrella Porter (iD, \\ Universidad San Francisco de Quito USFQ, \\ Quito, Ecuador \\ 2. Mithila Faruque (D), Bangladesh University \\ of Health Sciences (BUHS), Dhaka, \\ Bangladesh}

Any reports and responses or comments on the article can be found at the end of the article. 
Keywords

Mental health, migration, climate migrant, environmental migrant, eco migrant

This article is included in the Human Migration

Research gateway.

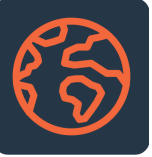

This article is included in the Climate gateway.

Corresponding author: Keren Herrán (heke1@umbc.edu)

Author roles: Herrán K: Conceptualization, Methodology, Writing - Original Draft Preparation, Writing - Review \& Editing; Biehler D: Conceptualization, Resources, Supervision, Validation, Writing - Review \& Editing

Competing interests: No competing interests were disclosed.

Grant information: University of Maryland, Baltimore County's Undergraduate Research Award grant provided funding for this work. The funders had no role in study design, data collection and analysis, decision to publish, or preparation of the manuscript.

Copyright: @ 2020 Herrán K and Biehler D. This is an open access article distributed under the terms of the Creative Commons Attribution License, which permits unrestricted use, distribution, and reproduction in any medium, provided the original work is properly cited.

How to cite this article: Herrán $\mathrm{K}$ and Biehler $\mathrm{D}$. Analysis of environmental migrants and their mental health in strengthening health systems [version 1; peer review: 2 approved with reservations] F1000Research 2020, 9:1367

https://doi.org/10.12688/f1000research.27272.1

First published: 24 Nov 2020, 9:1367 https://doi.org/10.12688/f1000research.27272.1 


\section{Introduction}

\section{Contextual overview}

Relevant human geography statistics. Scientists studying the nexus of climate change and human population movement predict that by 2050 , more than 250 million people will have migrated from their homelands due to climate-related change (Heaney \& Winter, 2016). Within Sub-Saharan Africa alone, it is estimated that there will be 86 million internal climate migrants by 2050 (Negev et al., 2019).

Our era's new migrants: Who are they? Escalation in anthropogenic greenhouse gases is increasing both the frequency and the intensity of extreme weather conditions and natural disasters (Schwerdtle et al., 2018). Those who are displaced by these changes or by their implications are often identified as climate migrants, environmental migrants, or eco migrants (International Organization for Migration, n.d.). Since climate change is not viewed as a force that acts alone in driving population displacement, these labels and their definitions are highly contested (Schwerdtle et al., 2018). It is also worth noting that these migrants are not recognized as refugees by international regulations, and thus labeling them as such is a misnomer (International Organization for Migration, n.d.).

The silent understudied health component of climate migration. Scholars have noticed a positive growth in governmental attention directed toward addressing the physical health consequences of climate change and climate migration, such as injuries and infectious disease (Torres \& Casey, 2017). However, researchers also increasingly stress that there is a dire need for discussion and study of the mental health consequences endured by eco migrants (Acharibasam \& Anuga, 2018; McMichael et al., 2012; Schwerdtle et al., 2018; Schwerdtle et al., 2019; Torres \& Casey, 2017). For instance, child and adolescent health specialists have been adamant in their concern and demand for studies on the state of mental health among environmental migrants (Myles et al., 2018). Children have been particularly vulnerable to post-disaster trauma given that their cognitive development does not prepare them for the witnessing of mass quantities of dead bodies (Hasan et al., 2020). Unfortunately, these mental scars are usually only exacerbated by the psychological stressors of climate migration (Schwerdtle et al., 2018). Despite pleas from professionals to invest in mental health evaluations and resources for environmental migrant populations, leaders and officials are often preoccupied by fighting for the provision of basic needs to these vulnerable communities and neglect addressing psychological concerns (Hasan et al., 2020; Nahar et al., 2014). This is especially unfortunate since there is evidence that environmental migrants themselves view their mental health as a valuable part of their overall health. In Tanzania, when asked what it meant to be healthy, "[climate] migrants placed more importance on mental health and non-migrants on physical health" (Heaney \& Winter, 2016, p.645).

\section{Research question}

Despite the advancing onset of climate change (and thus climate-driven migration), research on the health experiences of climate migrants is limited in regards to mental health knowledge. Therefore, this paper endeavors to answer the following question: What does the synthesis of available environmental migrant mental health studies reveal regarding environmental migrants' mental health and how health systems can be strengthened to best serve their psychological well-being?

\section{Methods}

The first author searched for the following phrases within Google Scholar: mental health of environmental migrants, environmental migrant mental health, climate migrant mental health, and eco migrant mental health, in order to find pertinent literature. For each phrase, search result pages one through six were reviewed to identify papers that met the following inclusion criteria: 1) The paper centered on environmental migrants as the population of focus for the study; 2) The manuscript directly discussed mental health experiences faced by climate migrants; 3) Published information was peer-reviewed and thus reliable; 4) Article had been released within the last 10 years and was thereby relatively recent.

Regarding reasons for exclusion, literature that focused on migrants in a general light and did not specifically analyze the experiences of eco migrants were not chosen for this narrative review. Papers that concentrated on physical health and mentioned mental health impacts briefly and only in passing were also omitted. In addition to direct searching, the technique of snowball searching was also utilized to identify scholarly information that relate to this analysis' research question and met inclusion criteria. Searching occurred during May of 2020 and stopped once data saturation was reached on May 23, 2020. Ultimately, 15 scientific studies were identified for review. Full text reading of manuscripts involved coding and categorizing information according to their relationship to the three distinct stages of migration: before, during, and after relocation. The authors also chose to supplement the narrative review with grey literature from the World Health Organization, news sources such as The Guardian and Gizmodo, and documentary films on climate migrants in Pacific Island countries. Inclusion criteria for grey literature were the same as the aforementioned criteria minus the requirement of peer-review validation. Grey literature was deemed reliable if affiliated with a larger recognized organization that collects primary data. All materials have been included in the reference list of this paper.

\section{Pre-existing mental health challenges among eco migrants}

Prevalence of issue

This section will examine what mental health disorders environmental migrants develop in the course of their experiences with climate change. It is important to comprehend their prior state of mental health since the stress of migrating to and entering into a new community can exacerbate or resurface previous psychological struggles. Anthropologist Dr. Lawrence Palinkas (2019) has stated that eco migrants are often, "able to bring little with them apart from the mental health problems created by the environmental changes [that caused them to move]" (p.2). According to the World Health Organization (WHO), up to half of all earthquake and tsunami survivors in South 
East Asia coastal lands suffer from post-disaster mental health issues that range from moderate to severe levels of distress (WHO, 2016). A population-based survey specific to south India reported that five years after the 2004 tsunami, around $78 \%$ of survivors continued to express symptoms of mental health morbidity (Hasan et al., 2020).

\section{Identification of specific mental health illnesses}

The main acute mental health disorders that result from witnessing sudden climate change disasters include post-traumatic stress disorder (PTSD), insomnia, depression, hopelessness and suicidal ideation, generalized anxiety disorder (GAD), and mood disorders (Acharibasam \& Anuga, 2018; Hasan et al., 2020; Palinkas, 2019). Past studies have concluded that even the anticipation of forced migration due to environmental changes significantly increases a community's level of depression (Torres \& Cassey, 2017). In communities where a climate change disaster has progressed gradually, such as extreme drought in the Central American Dry Corridor, mental health consequences such as stress and substance abuse are chronic (Acharibasam \& Anuga, 2018; Lakhani, 2019). The accumulation of years of unaddressed mental health imbalances in an individual can be distinctly detrimental since it interrupts their ability to accumulate human capital assets such as education (Palinkas, 2019).

New specific mental health diagnoses have also emerged as a result of anthropogenic environmental transformations. These new clinical illness categories include terms such as eco-anxiety and solastalgia (Palinkas, 2019; Tschakert et al., 2013). Whereas general anxiety is an unshakeable sense of concern and unease, eco-anxiety includes these sentiments in addition to the dread of existential threat due to climate change (Nugent, 2019). Solastalgia is the distress and isolation felt by no longer being able to find solace in the present condition of one's home environment (Palinkas, 2019).

\section{Lack of mental health support in home countries}

Many of those who are vulnerable to climate migration reside in countries where mental health care access is limited; thus, existing mental health issues often go unaddressed before migration (DW Documentary, 2017; Hanna \& Oliva, 2016; Hasan et al., 2020; Lakhani, 2019; McIver et al., 2016; Nahar et al., 2014; Torres \& Casey, 2017; Tschakert et al., 2013; Vorobyov, 2020). For instance, while Bangladesh ranks first worldwide in natural disaster mortality, the country only has one mental health hospital for its entire population (Nahar et al., 2014). This is a disservice to the mental health needs of natural disaster survivors in need of counsel and support after suffering from the trauma and loss of their loved ones or homes. With few resources for managing their illness appropriately, some individuals may turn to physical and sexual abuse of romantic partners or children as a coping mechanism (Hanna \& Oliva, 2016; Nahar et al., 2014). Such actions only further deteriorate the mental health of fellow victims of climate change.

What happens when those affected by climate change decide to migrate without support for recuperating their mental and emotional wellbeing? Will these populations receive support for their mental health along their journey, or have these needs overlooked, as in their home countries? These questions will be explored further in the subsequent section.

\section{Mental health risks along the climate migration journey}

Migration as a determinant of health

Based on investigations in Sub-Saharan Africa, Israeli public health investigators inferred that migration shapes health by disrupting access to health services and social networks of support (Negev et al., 2019). The researchers suggested that mobile phones and telemedicine technology ought to be optimized in order to provide care along migration routes. They also noted that health clinics should be established at key areas of repose along migration paths. Lack of access to physical health supports can be connected with poor mental health outcomes. If health services are not available for climate migrants along their route of travel, then treatment for other noncommunicable diseases, such as diabetes, is interrupted (Schwerdtle et al., 2019). Not having access to medication if one becomes ill or injured and not being able to receive needed medical treatment for noncommunicable diseases along migration routes can deteriorate a travelers' physical health. Consequently, worsened physical health can complicate one's ability to migrate, potentially causing a state of despair and decline in a migrant's mental health (Schwerdtle et al., 2018). Furthermore, since migrants may transit through regions with cultures and languages different than their own, this unfamiliarity with their surroundings and lack of protection places migrants at a, "greater risk of sexual exploitation, human trafficking, and sexual and gender-based violence" (Piguet et al., 2011, p.34; Palinkas, 2019). For migrants traveling with already delicate mental health states, undergoing such violations of their human rights only worsens their psychological and emotional wellbeing.

\section{Acknowledging the counterargument: Immigrant self- selection}

Some may reason that migration is not actually detrimental to climate migrants' mental health because their mental health is not unstable in the first place. This argument is based on the theory of immigrant self-selection. Economists explain immigrant self-selection as the conclusion that the, "healthiest and wealthiest individuals are the people most likely to migrate" (Kennedy et al., 2006, p.3). Under this mindset, the journey eco migrants undertake is not seen as an exacerbation of their prior mental health concerns because their mental health must by default have been steady beforehand for them to have been strong enough to assume the risks of migrating.

In contrast, some mental health researchers argue that, in certain circumstances, individuals do not fund their own displacement. Hence, the assumption that they must have robust health and come from a strong economic standing due to a privileged level in society that allows them to migrate, is false (Scaramutti et al., 2019). For example, after Hurricane Maria tore through Puerto Rico in 2017, the Federal Emergency Management Agency (FEMA) funded thousands of Puerto Ricans' 
displacement to Florida. Hence, those that left Puerto Rico were probably, "those who suffered the greatest personal and property losses during and after the storm" (Scaramutti et al., 2019, p.3). As the degree of duress on migrants increases, there may be a tendency for more unhealthy individuals to migrate. Diverse push and pull factors combined with different kinds of health conditions may lead to various levels of migration inhibition. In communities where climate change causes severe drought and famine, or results in an increase in armed conflict over limited resources, environmental migrants are essentially cornered. Just as staying in their hometowns would be a death sentence, deciding to leave and undertake the difficulties of traveling without guaranteed food, water, shelter, and protection from crime can also be mortal (Lakhani, 2019).

\section{Mental health challenges faced upon reaching destination community}

\section{Social marginalization}

Due to differences in cultural background, language, and legal status, receiving communities may treat eco migrants as inferior members of society (Heaney \& Winter, 2016; McMichael et al., 2012; Torres \& Casey, 2017; Vorobyov, 2020). This social stigma and discrimination can cause eco migrants to suffer from sentiments of isolation and depression. As reasoned by a citizen from the Republic of Kiribati (a country of islands that is disappearing due to sea level rise), "moving away to somewhere that does not belong to you, you will always become a second class person - in your heart you know you don't belong there" (DW Documentary, 2017, 27:45). The documentary, There Once Was an Island, portrays similar strains for people being displaced from the Takuu islands to Bougainville. Both Takuu and Bougainville islands are currently part of Papua New Guinea but have acutely distinct local communities and cultures (March \& Collie, 2010).

Recently in Brazil, farmers from the Northern region have had to relocate to cities in the South due to crop failure from excess heat and drought (Piguet et al., 2011). Given these migrants have limited funds as a result of unsuccessful harvest seasons, they often move to cheap housing in the slums, or "favelas," that are already overcrowded. In Brazil and other developing countries, rural to urban migration strains already overstretched resources of major cities (DW Documentary, 2017; McMichael et al., 2012). Brazil's current president, President Bolsonaro, has derided what he sees as a disorderly migration influx into favelas, limiting government investment and support. His harsh rhetoric towards favela dwellers, characterizing them as criminals, fails to set an example for how others should treat and welcome climate migrants with warmth in support of their mental health. Many have labeled these former agricultors as uneducated delinquents. These prejudices escalate migrants' likelihood of developing mental health illnesses (Vorobyov, 2020).

Host communities' hostility towards outsiders not only degrades the mental health of environmental migrants, but it can also prevent them from accessing mental health resources. Given that eco migrants already face extensive prejudice and discrimination, fear of further social stigmatization may deter them from seeking treatment for their mental health conditions (Heaney \& Winter, 2016). Furthermore, approaching public hospitals may be worrisome for eco migrants who lack legal status in the countries where they have relocated. Public health analysts have phrased this dilemma as a disadvantage that is, "exacerbated every time they must decide whether to interact with a system that may deport them" (Negev et al., 2019, p.1).

\section{Disruption of social ties}

Furthermore, an environmental migrant's relocation to another community can adversely impact their mental health due to migration's tendency to disrupt social ties (Heaney \& Winter, 2016; McMichael et al., 2012; Schwerdtle et al., 2018; Torres \& Casey, 2017). Friends and family members that migrants leave behind constitute an important support network that migrants were previously able to count on for emotional support, guidance, and resources (Torres \& Casey, 2017). Stripped of these systems of resilience and surrounded by a new group of people that may not be supportive of their presence, eco migrants can find it difficult to maintain optimal mental health. Although technology bridges this gap to a certain extent, studies have shown that when individuals are separated, the mental health of those who stay in situ is as equally aggravated as the mental health of those who migrate (Schwerdtle et al., 2018). Therefore, since the mental health of those who are left may also suffer after community members migrate, their ability to provide substantial encouragement remotely via technology is questionable. In fact, if the well-being of those in situ amid environmental disaster is poor, this may exacerbate the mental health of those who did migrate. Furthermore, climate migrants' responsibility to send remittance obligations to financial dependents back home can drain their mental health since it is yet another burden they must bear in their stressful transition and adaptation to a new location (Heaney \& Winter, 2016; Torres \& Casey, 2017).

The grass is not always greener on the other side When climate change directly or indirectly forces one to leave their home in search of a better quality of life, it does not always lead one to a destination with fewer mental health threats. In fact, the end of a climate migrant's journey may be a city with more job opportunities at the expense of exposure to even more environmental threats than before (McMichael et al., 2012; Piguet et al., 2011). For example, environmental migrants arriving to favelas in Brazil often lack electricity, water, hygienic living spaces, and basic services as a result of their rural to urban migration (Vorobyov, 2020). Apart from the fact that climate migrants' mental health may be further aggravated by their new community, not living on their land of origin and changing livelihoods can also deteriorate their sense of identity (Acharibasam \& Anuga, 2018; March \& Collie, 2010; McMichael et al., 2012; Tschakert et al., 2013). Geographers and anthropologists have noted that, "there is an intimate relationship between people and their everyday landscapes," and that hence, losing one's sense of place can cause collateral psychological damage (Tschakert et al., 2013, p.14). 


\section{Conclusion}

Social justice for the vulnerable

It would be an injustice to collect, organize, and scrutinize as much information as possible about the mental health consequences of environmental migration without shedding light on what can be done to mitigate the phenomenon. From a medical sociology standpoint it is indeed, "a matter of social justice to invest in the mental health of these populations in motion" (Torres \& Casey, 2017, p.8). Climate change repeatedly victimizes the poor since their economic levels limit their housing options to environmentally risky areas that lack protective infrastructure (Hanna \& Oliva, 2016; Lakhani, 2019; McIver et al., 2016; Nahar et al., 2014; Scaramutti et al., 2019; Torres \& Casey, 2017; Tschakert et al., 2013). Environmental transformations and destructions ironically impact developing countries the most, contributing to a cycle of disempowerment and vulnerability despite the fact that developing nations are the smallest contributors to climate change (McIver et al., 2016; Piguet et al., 2011; Vorobyov, 2020). It is also important to recognize that females' mental health is all the more endangered by eco migration because they are exposed to additional traumatic events such as lack of autonomy upon widowhood, gender based violence, and sexual exploitation (Hasan et al., 2020; McMichael et al., 2012; Nahar et al., 2014; Palinkas, 2019; Piguet et al., 2011, p.34). Taking into consideration the synthesis of information presented thus far and the unique vulnerabilities that add to its complexity, the remaining end of this paper will proceed to outline action items health systems ought to take.

\section{Strengthening health systems: Climate resilience and inclusion of eco migrants}

To clarify, addressing the mental health of climate migrants will demand support and collaboration at multiple levels worldwide. Given the multidimensional nature of the issue, a truly sustainable and effective solution will likewise require interdisciplinary investment (Nahar et al., 2014; McMichael et al., 2012; Torres \& Casey, 2017). It will necessitate expertise from international development workers, gender and women's studies experts, policymakers, nations' leading economists, public health strategists, and technology innovators, among other professionals. Thus assigning recommendations specific to health systems should be seen as suggestions only worthwhile if part of a larger global plan of intervention. Such a plan will undoubtedly also entail further research on the crisis.

First and foremost, across publications, there is widespread agreement that health systems should endeavor to fight structural barriers that impede climate migrant's access to health services (Hasan et al., 2020; Negev et al., 2019; Schwerdtle et al., 2019). For instance, as previously stated, concerns over uncovering personal legal status may dissuade climate migrants from seeking treatment for their mental health (both along their journey and once at their destination). Therefore, health systems along migration routes and within countries that receive migrants should brainstorm how they can intake patients without asking for information that patients do not wish to disclose due to fear of deportation (Negev et al., 2019). Furthermore, since this subdivision of migrants is often economically disadvantaged, healthy systems need to implement pro bono/free/non-compensated mental health counseling services options that remove any financial barriers. An exemplary model of successful allocation of funds toward complementary mental health services would be the healthcare facilities in Arusha, Tanzania that, "provide free psychiatric and psychological counseling to underprivileged populations," given it is an area where many environmental migrants resettle (Negev et al., 2019, p. 312). Social policy experts and the WHO also increasingly stress that healthcare professionals train community health workers and non-professionals in psychological first aid interventions to improve their range of outreach (Nahar et al., 2014; Palinkas, 2019). This may resolve access barrier issues that relate to lacking transportation to health services.

However, regardless of the preceding fundamental action items, eco migrants are unaware of even the current mental health services they have available (Heaney \& Winter, 2016). Health systems must recognize that development and expansion of programming is futile if these efforts are not effectively promoted so that eco migrants know what is available to them. Hence, healthcare strategists should also reflect on information dissemination methods and how to reduce stigma surrounding the notion of seeking assistance for mental health.

In conclusion, although natural disasters and drastic changes in weather can be unpredictable, climate change "loads the dice" in favor of increasing incidence of natural disasters (Hansen et al., 2012). By reflecting on current mental health information related to climate migrants, efforts to assist these migrants in their healing and restoration of mental wellbeing can and should be achieved while conducting further research in this area.

\section{Data availability}

Underlying data

All data underlying the results are available as part of the article and no additional source data are required.

\section{Acknowledgements}

The author would like to thank her mentor Dr. Dawn Biehler for encouraging her to research this topic and for contributing to the author's academic and professional development. 
Acharibasam JW, Anuga SW: Psychological distance of climate change and mental health risks assessment of smallholder farmers in Northern Ghana: Is habituation a threat to climate change? Clim Risk Manag. 2018; 21: 16-25.

Publisher Full Text

DW Documentary: Kiribati: a drowning paradise in the South Pacific. [Video file]. 2017

Reference Source

Hanna R, Oliva P: Implications of climate change for children in developing countries. Future Child. 2016; 115-132.

Reference Source

Hansen J, Sato M, Ruedy R: Perception of climate change. Proc Natl Acad Sci. 2012; 109: 14726-14727.

PubMed Abstract | Publisher Full Text | Free Full Text

Hasan MT, Adhikary G, Mahmood S, et al.: Exploring mental health needs and services among affected population in a cyclone affected area in costal Bangladesh: a qualitative case study. Int J Ment Health Syst. 2020; 14(1): 12 PubMed Abstract | Publisher Full Text | Free Full Text

Heaney AK, Winter SJ: Climate-driven migration: an exploratory case study of Maasai health perceptions and help-seeking behaviors. Int J Public Health. 2016; 61(6): 641-649.

PubMed Abstract | Publisher Full Text

International Organization for Migration: Key Migration Terms. n.d.

Reference Source

Kennedy S, McDonald JT, Biddle N: The healthy immigrant effect and immigrant selection: evidence from four countries. 2006.

Reference Source

Lakhani N: Running dry. 2019.

Reference Source

March B, Collie L: There Once was an Island: Te Henua e Nnoho. New Day Films. 2010.

McIver L, Kim R, Woodward A, et al.: Health Impacts of Climate Change in Pacific Island Countries: A Regional Assessment of Vulnerabilities and Adaptation Priorities. Environ Health Perspect. 2016; 124(11): 1707-1714. PubMed Abstract | Publisher Full Text | Free Full Text

McMichael C, Barnett J, McMichael AJ: An ill wind? Climate change, migration, and health. Environ Health Perspect. 2012; 120(5): 646-654.

PubMed Abstract | Publisher Full Text | Free Full Text

Myles $P$, Swenshon S, Haase $K$, et al.: A comparative analysis of psychological

trauma experienced by children and young adults in two scenarios:

evacuation after a natural disaster vs forced migration to escape armed conflict Public health. 2018: 158: 163-175.

PubMed Abstract | Publisher Full Text

Nahar N, Blomstedt $Y$, Wu B, et al.: Increasing the provision of mental health care for vulnerable, disaster-affected people in Bangladesh. BMC Public

Health. 2014; 14(1): 708.

PubMed Abstract | Publisher Full Text | Free Full Text

Negev M, Teschner NA, Rosenthal A, et al.: Adaptation of health systems to climate-related migration in Sub-Saharan Africa: Closing the gap. Int J Hyg Environ Health. 2019; 222(2): 311-314.

PubMed Abstract | Publisher Full Text

Nugent C: Terrified of Climate Change? You Might Have Eco-Anxiety. Health - Climate. 2019.

Reference Source

Palinkas LA: Climigrants. 2019.

Reference Source

Piguet E, Pécoud A, de Guchteneire P, et al.: Migration and climate change. Cambridge University Press. 2011; 31-34.

Reference Source

Scaramutti C, Salas-Wright CP, Vos SR, et al.: The Mental Health Impact of Hurricane Maria on Puerto Ricans in Puerto Rico and Florida. Disaster Med Public Health Prep. 2019; 13(1): 24-27.

PubMed Abstract | Publisher Full Text

Schwerdtle PN, Bowen K, McMichael C, et al.: Human mobility and health in a warming world. J Travel Med. 2019; 26(1): tay160.

PubMed Abstract | Publisher Full Text

Schwerdtle P, Bowen K, McMichael C: The health impacts of climate-related migration. BMC Med. 2018; 16(1): 1

PubMed Abstract | Publisher Full Text | Free Full Text

Torres JM, Casey JA: The centrality of social ties to climate migration and mental health. BMC public health. 2017; 17(1): 600

PubMed Abstract | Publisher Full Text | Free Full Text

Tschakert P, Tutu R, Alcaro A: Embodied experiences of environmental and climatic changes in landscapes of everyday life in Ghana. Emot Space Soc. 2013: 7: 13-25.

Publisher Full Text

Vorobyov N: Brazil is Cracking Down on Climate Migrants While Worsening the Climate Crisis. 2020.

Reference Source

World Health Organization: Disasters and Mental Health. 2016.

Reference Source 


\section{Open Peer Review}

\section{Current Peer Review Status: ? ?}

\section{Version 1}

Reviewer Report 23 February 2021

https://doi.org/10.5256/f1000research.30136.r77714

(C) 2021 Faruque $\mathbf{M}$. This is an open access peer review report distributed under the terms of the Creative Commons Attribution License, which permits unrestricted use, distribution, and reproduction in any medium, provided the original work is properly cited.

\section{Mithila Faruque}

Department of Noncommunicable Diseases, Faculty of Public Health, Bangladesh University of Health Sciences (BUHS), Dhaka, Bangladesh

The author tried to highlight a very important issue regarding the eco-migrants mental health which should have been emphasized a long before the era. Definitely the health system of the country where this type of environmental or climate change impacts are prominent should have a specific intervention strategy at the policy level to address the mental health needs of the migrants.

But regrding methodology, I would like to mention that the author should include a flow chart with the reviewed literature serching pattern and numbers with and without inclusion criteria (before and after), so that the readers have a clear idea about the literature searching process. At present, the method is clumsy and review process is not understandable.

Also need a clear visualization of the findings analysed from the reviewed literature. So the author is requested to add a table with highlighting the summary of findings obtained from the literature with reference list.

Conclusion is too big, I suggest to concise the conclusion with including a part of recommendations from the obtained findings form the review.

Is the work clearly and accurately presented and does it cite the current literature? Yes

Is the study design appropriate and is the work technically sound? Partly

Are sufficient details of methods and analysis provided to allow replication by others? Partly 


\section{If applicable, is the statistical analysis and its interpretation appropriate? Not applicable}

\section{Are all the source data underlying the results available to ensure full reproducibility? No source data required}

\section{Are the conclusions drawn adequately supported by the results? Yes}

Competing Interests: No competing interests were disclosed.

Reviewer Expertise: My field of research interest is noncommunicable diseases like epidemiology and risk factors of hypertension, cardiovascular disease, diabetes, chronic respiratory diseases, cancer and their prevention management. Also strengthening primary health care system for the prevention and control of NCDs.

\section{I confirm that I have read this submission and believe that I have an appropriate level of expertise to confirm that it is of an acceptable scientific standard, however I have significant reservations, as outlined above.}

Reviewer Report 01 February 2021

\section{https://doi.org/10.5256/f1000research.30136.r75979}

(c) 2021 Estrella Porter P. This is an open access peer review report distributed under the terms of the Creative Commons Attribution License, which permits unrestricted use, distribution, and reproduction in any medium, provided the original work is properly cited.

\section{Pablo Daniel Estrella Porter}

Escuela de Medicina, Universidad San Francisco de Quito USFQ, Quito, Ecuador

The global health migration crisis has become one of the issues that are threatening human society worldwide. This research article has raised an important approach to the migration crisis, centering on the mental health area. The analysis presents an overview of the mental health situation on the three stages of migration: before, during, and after the relocation. The different disorders of the mental health illnesses were identified, as well as the baseline situation of many migrants, and the challenges faced upon arrival. The authors acknowledged the need to involve different stakeholders and decision-making actors, to generate positive changes on environmental migration.

To make this research more impactful, the methodology could have been strengthened. For example, using a qualitative-systematic review, where research evidence could be collected, analyzed, and presented in a framework where is easier to replicate and summarize. The manuscript could have benefited from presenting the total scientific studies found before using the inclusion and exclusion criteria or using a simplified version of a PRISMA diagram to present the results. Furthermore, including a table with a summary of the main findings of each paper that 
went to full-text reading, would have increased the relevance of the results and conclusions of this analysis.

Although the document presents a highly relevant topic, the structure of the article could be improved to give a better understanding. In such a way that the information collected from the selected scientific studies is presented more sequentially and the subsequent analysis is done afterward.

Nonetheless, the results obtained from this research are important to show the need for greater intervention and action in mental health in this emerging group of environmental migrants that is growing every day.

\section{References}

1. Obokata R, Veronis L, McLeman R: Empirical research on international environmental migration: a systematic review.Popul Environ. 2014; 36: 111-135 PubMed Abstract | Publisher Full Text

2. Stovold E, Beecher D, Foxlee R, Noel-Storr A: Study flow diagrams in Cochrane systematic review updates: an adapted PRISMA flow diagram. Systematic Reviews. 2014; 3 (1). Publisher Full Text

3. Torres J, Casey J: The centrality of social ties to climate migration and mental health. BMC Public Health. 2017; 17 (1). Publisher Full Text

Is the work clearly and accurately presented and does it cite the current literature? Yes

Is the study design appropriate and is the work technically sound?

Yes

Are sufficient details of methods and analysis provided to allow replication by others? Partly

If applicable, is the statistical analysis and its interpretation appropriate?

Not applicable

Are all the source data underlying the results available to ensure full reproducibility? No source data required

Are the conclusions drawn adequately supported by the results? Yes

Competing Interests: No competing interests were disclosed.

Reviewer Expertise: Public Health, Medical Education, General Medicine, and Global Health.

I confirm that I have read this submission and believe that I have an appropriate level of expertise to confirm that it is of an acceptable scientific standard, however I have significant reservations, as outlined above. 
The benefits of publishing with F1000Research:

- Your article is published within days, with no editorial bias

- You can publish traditional articles, null/negative results, case reports, data notes and more

- The peer review process is transparent and collaborative

- Your article is indexed in PubMed after passing peer review

- Dedicated customer support at every stage

For pre-submission enquiries, contact research@f1000.com 